\title{
INFLUÊNCIA DA COMPACTAÇÃO DO SOLO NO CRESCIMENTO DE MILHO (ZEA MAYS L.) EM LATOSSOLO VERMELHO-AMARELO
}

Kalline Almeida Alves Carneiro ${ }^{1}$, Flávio Pereira de Oliveira ${ }^{1}$, Maria Cristina Santos Pereira de Araujo ${ }^{1}$, Leandro Firmino Fernandes ${ }^{1}$, Ewerton Gonçalves de Abrantes ${ }^{1}$, Jhony Vendruscolo ${ }^{2}$

${ }^{1}$ Universidade Federal da Paraíba - UFPB. ${ }^{2}$ Fundação Universidade Federal de Rondônia - UNIR. E-mail: ewertonagroti@hotmail.com; pereira@cca.ufpb.br

\section{RESUMO}

A compactação do solo constitui um fator limitante ao crescimento e desenvolvimento vegetativo, reduzindo a produtividade agrícola. Neste contexto, objetivou-se com o presente trabalho, avaliar os efeitos da profundidade da camada compactada e do nível de compactação de um Latossolo VermelhoAmarelo distrófico no crescimento de plântulas de milho. O delineamento experimental foi inteiramente casualizado, em parcelas subdividas no tempo, disposto em um esquema fatorial $2 \times 2+1$, sendo duas densidades do solo $\left(1,5\right.$ e $\left.1,7 \mathrm{~g} \mathrm{~cm}^{-3}\right)$, duas profundidades da camada compactada $(0-3 \mathrm{~cm} \mathrm{e} 8-11 \mathrm{~cm})$ e um controle com densidade natural do solo $\left(1,3 \mathrm{~g} \mathrm{~cm}^{-3}\right)$, com três repetições. Foi cultivado o milho híbrido AG 1051 em colunas durante o período de 38 dias. Durante o período experimental, foram avaliados: a área foliar (AF), o número de folhas (NF), o diâmetro do caule (DC), comprimento do caule (CC), volume radicular (VR), massa seca foliar (MSF), do caule (MSC) e das raízes (MSR), a taxa de crescimento absoluto (TCA) e relativo (TCR). De acordo com os resultados obtidos, o aumento da densidade do solo promoveu alterações morfológicas no diâmetro do caule (DC), e no volume da raiz (VR), e, consequentemente, na massa seca da raiz (MSR) e massa seca total (MST). A compactação na camada superficial é mais prejudicial ao crescimento da cultura do que na camada subsuperficial.

Palavras-chave: camada de impedimento; densidade do solo; resistência à penetração.

\section{INFLUENCE OF SOIL COMPACTION IN THE GROWTH OF MAIZE (ZEA MAYS L.) IN OXISOL}

\begin{abstract}
Soil compaction is a limiting factor to growth and vegetative development, reducing agricultural productivity. In this context, the aim of the present study was to evaluate the effects of the depth of the compacted layer and the level of compaction of a Dystrophic Red-Yellow Oxisol on the growth of maize seedlings. The experimental design was completely randomized in split plots in time, arranged in a factorial $2 \times 2+1$, being two soil densities $\left(1.5\right.$ and $\left.1.7 \mathrm{~g} \mathrm{~cm}^{-3}\right)$, two layers of compacted layer $(0-3 \mathrm{~cm}$ and $8-11$ $\mathrm{cm}$ ) and a control with natural soil density $\left(1.3 \mathrm{~g} \mathrm{~cm}^{-3}\right)$, with three replications. Hybrid maize AG 1051 were cultivated in columns, over the period of 31 days. During the trial period, were evaluated: the leaf area (LA), the number of leaves (NL), stem diameter (SD), stem length (SL), root volume (RV), leaves dry matter (LDM), stem (SDM) and root (RDM), the absolute growth rate (AGR) and relative (RGR). According to the results, the increase in soil density promoted morphological changes in stem diameter, and the volume of the root, and consequently, the root dry mass and total dry matter. The compression in the surface layer is more harmful to crop growth than in the subsurface layer.
\end{abstract}

Keywords: bulk density; impediment layer; penetration resistance.

\section{INTRODUÇÃO}

A compactação reduz e reorienta os poros do solo, com efeito mais acentuado sobre a macroporosidade, esse efeito pode ser ocasionado pelo tráfego de máquinas agrícolas e persistir por dois anos (SORACCO et al., 2015). A alteração na porosidade do solo geralmente resulta em diminuições da infiltração (MANCUSO et al., 2014), retenção e disponibilidade de água (KLEIN; KLEIN, 2014), trocas gasosas, 
disponibilidade de nutrientes (FREDDI et al., 2009a; 2009b) e atividade microbiana (MIRANSARI, 2013), afetando negativamente o crescimento e o desenvolvimento do sistema radicular (SOUZA et al., 2018).

Devido a influência da compactação nas características morfológicas das plantas, estudos são realizados para orientar o manejo e prevenir perdas de produtividade nas culturas agrícolas. Atualmente, sabe-se que a magnitude dos problemas causados pela compactação do solo depende do tipo de solo, espécie utilizada e nível de compactação (RODRIGUES et al., 2009). Em cultivos de milho (Zea mays L.) em Latossolo Vermelho compactado, por exemplo, aumenta-se o diâmetro e diminui-se o comprimento das raízes, que se tornam tortuosas (BERGAMIN et al., 2010), reduzindo o volume de solo explorado para obtenção de água e nutrientes, e consequentemente, a produtividade (FREDDI et al., 2009a). Os estudos descritos trabalharam com a compactação na camada superficial, surgindo a pergunta, se a camada compactada fosse subsuperficial os efeitos seriam os mesmos?

A resposta da pergunta tem grande importância no setor agrícola brasileiro, principalmente com relação ao milho, considerada a segunda cultura mais cultivada no País, com uma área de 16.631 .800 ha nos anos de 2017/18 (produção de 80.780.652,6 t), atrás somente da soja (Glycine Max (L.) Merr.) (CONAB, 2019). Também é interessante salientar que a preocupação direcionada principalmente para os efeitos da compactação na camada subsuperficial do solo, por ser mais visível, pode significar reduções significativas na produção nacional e no retorno econômico dos produtores.

Diante do exposto, objetivou-se avaliar os efeitos da profundidade da camada compactada e do nível de compactação de um Latossolo Vermelho-Amarelo distrófico no crescimento de plântulas de milho.

\section{MATERIAL E MÉTODOS}

O experimento foi realizado em casa de vegetação situada no Centro de Ciências Agrárias da Universidade Federal da Paraíba, Areia, Paraíba, em colunas experimentais de PVC rígido de $100 \mathrm{~mm}$, com capacidade de $1,57 \mathrm{dm}^{3}$.

O solo utilizado no presente estudo foi proveniente de áreas em cultivo, e contempla uma das principais classes de solo identificadas na região, o Latossolo Vermelho-Amarelo distrófico, com textura argilo-arenosa. O clima da região é classificado como Zona Tropical com verão seco (As) (ALVARES et al., 2014).

Para o trabalho, foram coletadas amostras na camada de $0-20 \mathrm{~cm}$ de profundidade, seco ao ar e passado em peneira com malha de $2 \mathrm{~mm}$, e posteriormente submetido à caracterização química e física. $\mathrm{Na}$ caracterização química foram determinados: $\mathrm{o} \mathrm{pH}$ em água, os teores trocáveis de $\mathrm{Na}^{+}, \mathrm{K}^{+}, \mathrm{Ca}^{2+}$, $\mathrm{Mg}^{2+}, \mathrm{Al}^{3+}$ e $\mathrm{H}+\mathrm{Al}$, o teor de matéria orgânica. Para a caracterização física, foi realizado a avaliação granulométrica, utilizando-se $\mathrm{NaOH}$ como agente dispersante. Todas as análises foram realizadas conforme Donagema et al. (2011) (Tabela 1).

Tabela 1.Resultado das Análises químicas de físicas e químicas do solo um Latossolo Vermelho-Amarelo distrófico, na camada de $0-20 \mathrm{~cm}$ de profundidade.

\begin{tabular}{cccc}
\hline Atributos químicos & \multicolumn{3}{c}{ Atributos físicos } \\
\hline $\mathrm{pH} \mathrm{H}{ }_{2} \mathrm{O}(1: 2,5)$ & 4,91 & Densidade do solo $\left(\mathrm{g} \mathrm{cm}^{-3}\right)$ & 1,19 \\
$\mathrm{Na}^{+}\left(\mathrm{cmol}_{c} \mathrm{dm}^{-3}\right)$ & 0,02 & Densidade das partículas $\left(\mathrm{g} \mathrm{cm}^{-3}\right)$ & 2,79 \\
$\mathrm{~K}^{+}\left(\mathrm{cmol}_{c} \mathrm{dm}^{-3}\right)$ & 0,07 & Porosidade total $(\%)$ & 57,4 \\
$\mathrm{Ca}^{2+}\left(\mathrm{cmol}_{c} \mathrm{dm}^{-3}\right)$ & 1,24 & Areia $\left(\mathrm{g} \mathrm{kg}^{-1}\right)$ & 469 \\
$\mathrm{Mg}^{2+}\left(\mathrm{cmol}_{\mathrm{c}} \mathrm{dm}^{-3}\right)$ & 1,50 & Silte $\left(\mathrm{g} \mathrm{kg}^{-1}\right)$ & 1040 \\
$\mathrm{Al}^{3+}\left(\mathrm{cmol}_{c} \mathrm{dm}^{-3}\right)$ & 0,80 & Argila $\left(\mathrm{g} \mathrm{kg}^{-1}\right)$ & 427 \\
$\mathrm{H}+\mathrm{Al}\left(\mathrm{cmol}_{\mathrm{c}} \mathrm{dm}^{-3}\right)$ & 8,73 & Classe textural & Argilo arenoso \\
$\mathrm{SB}\left(\mathrm{cmol}_{\mathrm{c}} \mathrm{dm}^{-3}\right)$ & 2,81 & & \\
$\mathrm{~T}\left(\mathrm{cmol}_{\mathrm{c}} \mathrm{dm}^{-3}\right)$ & 12.34 & & \\
$\mathrm{~V}(\%)$ & 22,8 & & \\
$\mathrm{P}\left(\mathrm{mg} \mathrm{dm}^{-3}\right)$ & 0,22 & & \\
Matéria orgânica $\left(\mathrm{g} \mathrm{kg}^{-1}\right)$ & 13,9 & & \\
\hline${ }^{1}$ Metodologia conforme Donagema et al. (2011); SB - soma de bases; $\mathrm{T}-\mathrm{CTC}$ potencial; $\mathrm{V}$ - saturação por bases.
\end{tabular}


As colunas experimentais com camadas compactadas foram confeccionadas através da sobreposição e encaixe de dois anéis de PVC rígido, simulando uma compactação superficial Coluna A (0 - $3 \mathrm{~cm}$ de profundidade); uma compactação subsuperficial - Coluna B $(8,5$ a $11,5 \mathrm{~cm}$ de profundidade) semelhante o efeito do pé-de-arado; e, uma Coluna $C(20 \mathrm{~cm}$ de profundidade) que não apresenta camada compactada, considerada a testemunha (Figura
1). Na face interna das colunas foi pincelada uma mistura de cola branca e areia lavada, visando evitar o crescimento preferencial das raízes na interface solo-PVC. A compactação das camadas de solo foi realizada utilizando um equipamento compactador, considerando a massa de solo e o volume do anel de $0,03 \mathrm{~m}$ de altura, para obtenção das densidades desejadas, de 1,5 e 1,7 $\mathrm{g} \mathrm{cm}^{-3}$.

Figura 1. Classificação das colunas em função da profundidade da camada compactada.

A

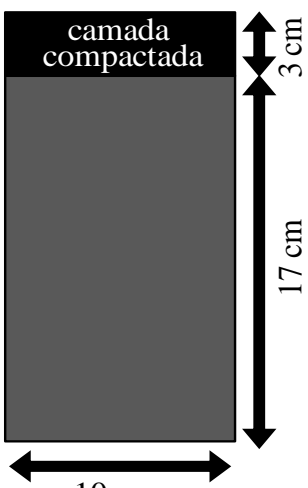

$10 \mathrm{~cm}$
B

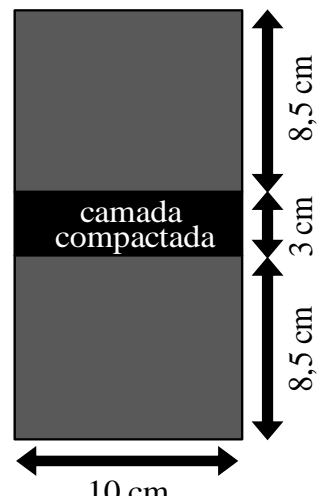

C

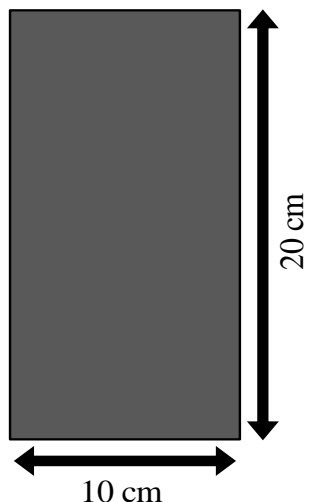

O delineamento experimental adotado foi inteiramente casualizado, em esquema fatorial $2 \times 2+1$, com parcelas subdivididas no tempo, com três repetições. Os tratamentos consistiram de combinações entre as densidades do solo (DS) e a profundidade da camada compactada, sendo: T1: camada compactada aos 0-3 cm e DS de 1,5 $\mathrm{g} \mathrm{cm}^{-3} ; \mathrm{T2}$ : camada compactada aos 0-3 cm e DS de $1,7 \mathrm{~g} \mathrm{~cm}^{-3}$; T3: camada compactada aos $8,5-11,5 \mathrm{~cm}$ e DS de 1,5 $\mathrm{g} \mathrm{cm}^{-3}$; T4: camada compactada aos 8,5-11,5 cm e DS de $1,7 \mathrm{~g} \mathrm{~cm}^{-3}$; Testemunha: sem camada compactada e densidade de $1,3 \mathrm{~g} \mathrm{~cm}^{-3}$.

Em cada coluna foram plantadas cinco sementes de milho híbrido AG1051, sendo realizado o desbaste cinco dias após emergência (DAE), deixando-se as duas plantas mais vigorosas. As plantas selecionadas foram cultivadas por 38 dias após o plantio (DAP), mantendo-se o teor de água em $75 \%$ da capacidade de campo.

\section{Avaliação do crescimento}

Para a avaliação do crescimento do milho foram analisadas: a massa seca foliar (MSF), do caule (MSC), das raízes (MSR) e total (MST), correspondente ao somatório da MSF, MSC e MSR, a área foliar (AF), o número de folhas (NF), o diâmetro do caule (DC), comprimento do caule (CC), volume radicular (VR), a taxa de crescimento absoluto (TCA) e relativo (TCR). As avaliações ocorreram aos 10, 17, 24, 31 e 38 DAP.

Para estimar o VR, inicialmente separaram-se as raízes do solo utilizando peneira e água corrente, posteriormente aplicou-se o princípio de Arquimedes, imergindo o material em proveta graduada contendo água e anotando o volume de água deslocada. A TCA foi estimada conforme a equação1:

TCA $\left(\mathrm{g} \mathrm{dia}^{-1}\right)=\left(\mathrm{MS}_{2}-\mathrm{MS}_{1}\right) /\left(\mathrm{t}_{2}-\mathrm{t}_{1}\right)(1)$

Onde: $\mathrm{MS}_{1}=$ matéria seca acumulada na avaliação anterior $(\mathrm{g}) ; \mathrm{MS}_{2}=$ matéria seca acumulada na avaliação atual $(\mathrm{g}) ; \mathrm{t}_{1}=$ tempo em DAP da avaliação anterior (dias); $t_{2}=$ tempo em DAP da avaliação atual (dias).

A TCR foi estimada conforme a equação2:

$\mathrm{TCR}\left(\mathrm{g} \mathrm{g}^{-1} \mathrm{dia}^{-1}\right)=\left(\ln \mathrm{MS}_{2}-\ln \mathrm{MS}_{1}\right) /\left(\mathrm{t}_{2}-\mathrm{t}_{1}\right)(2)$ Onde: In refere-se ao logaritmo neperiano.

\section{Análise dos dados}

Os dados obtidos foram tabulados e submetidos à análise de variância, os tratamentos foram comparados pelo teste de Tukey $(p<0,05)$ e o efeito do tempo de avaliação por análise de regressão, realizando-se os desdobramentos pertinentes quando observado 
a interação entre os fatores, conforme critérios de resposta biológica, significância do modelo e o coeficiente de correlação. Os desdobramentos foram realizados quando observados efeitos de forma isolada de ambos os fatores, e/ou interacional. Os valores referentes aos tratamentos também foram submetidos a análise de contraste ortogonal para comparar o efeito da testemunha com os demais tratamentos. As análises foram realizadas utilizando pacote estatístico SISVAR ${ }^{\circledR}$ (FERREIRA, 2011).

\section{RESULTADOS E DISCUSSÃO}

A TCA e a TCR foram as únicas variáveis não influenciadas significativamente pelos tratamentos (Tabela 2). Também se constatou que todas as variáveis obtiveram efeito significativo em função da época de avaliação, ocorrendo interação em MSR, MST, DC, VR, TCA e TCR.

Tabela 2. Quadrados médios do resíduo para as variáveis em função dos tratamentos e das épocas de avaliação.

\begin{tabular}{cccccc}
\hline Fonte de variação & MSF & MSC & MSR & MST & NF \\
\hline Tratamento (T) & $0,094^{* *}$ & $0,065^{* *}$ & $6,910^{* *}$ & $10,729^{* *}$ & $1,02^{*}$ \\
Época (E) & $0,550^{* *}$ & $0,481^{* *}$ & $2,682^{* *}$ & $9,129^{* *}$ & $6,687^{* *}$ \\
T $\times$ E & $0,018^{\text {ns }}$ & $0,026^{\text {ns }}$ & $0,850^{* *}$ & $1,278^{* *}$ & $0,353^{\text {ns }}$ \\
CV 1 (\%) & 22,28 & 41,63 & 45,27 & 35,88 & 10,94 \\
CV 2 (\%) & 30,39 & 42,96 & 60,47 & 42,79 & 11,09 \\
\hline Fonte de variação & AF & DC & VR & TCA & TCR \\
\hline Tratamento (T) & $78,426^{* *}$ & $0,031^{* *}$ & $265,225^{* *}$ & $0,008^{\text {ns }}$ & $0,001^{\text {ns }}$ \\
Época (E) & $495,056^{* *}$ & $0,276^{* *}$ & $43,933^{* *}$ & $0,072^{*}$ & $0,023^{* *}$ \\
T × E & $21,074^{\text {ns }}$ & $0,007^{*}$ & $14,929^{* *}$ & $0,061^{* *}$ & $0,005^{*}$ \\
CV 1 (\%) & 16,1 & 14,77 & 25,46 & 14,14 & 19,01 \\
CV 2 (\%) & 13,83 & 12,37 & 26,54 & 16,26 & 26,01 \\
\hline
\end{tabular}

MSF: matéria seca foliar; MSC: matéria seca do caule; MSR: matéria seca da raiz; MST: matéria seca total; NF: número de folhas; AF: área foliar; DC: diâmetro do caule; VR: volume radicular; TCA: taxa de crescimento absoluto; TCR: taxa de crescimento relativo; * ${ }^{* *}$ : Significativos 5 e $1 \%$ pelo teste de Tukey, respectivamente.

A produção de MSF aumentou em todos os tratamentos em virtude do crescimento vegetativo do milho, com ponto de inflexão próximo aos 31 DAP, com exceção para o tratamento $T 3$, que manteve crescimento linear. Aos 31 DAP, o valor máximo de MSF observado ocorreu na Testemunha, que foi de aproximadamente $0,9 \mathrm{~g} \mathrm{planta}^{-1}$ (Figura 2A). No entanto, observou-se também que nas plantas submetidas à compactação superficial aliada à maior densidade do solo (T2), obteve-se o menor acúmulo de MSF entre os tratamentos.

Nos tratamentos T3 e T4 com compactação subsuperficial, a MSF foi inferior a testemunha, vale salientar que o período de avaliação pode ter sido insuficiente para que houvesse a inflexão da curva de crescimento do milho, mas essa condição que não impediu o menor crescimento das plantas em virtude da camada de impedimento ao desenvolvimento do sistema radicular.

Os resultados sugerem que a compactação do solo reduz a MSF independente da profundidade da camada. Porém, ao ocorrer na camada superficial o problema é potencializado, devido à baixa disponibilidade de água e nutrientes para o estabelecimento da planta, a qual demanda grande quantidade de energia para desenvolver o sistema radicular.

A produção de MSC elevou-se em função da época de avaliação, com maior tendência de crescimento na Testemunha, T4 e T1, respectivamente (Figura 2B). Na Testemunha e no T1 observaram-se tendências cúbicas, com a curva apresentando o ponto de inflexão no $34^{\circ}$ DAP. O comportamento da Testemunha está associado com o crescimento da planta, que excedeu o volume do cilindro, limitando a disponibilidade de água e nutrientes (CABRAL et al., 2012). O comportamento do T1 está relacionado com a restrição imposta pela camada compactada desde o início do estabelecimento das plantas, que reduziu o volume de solo explorado, a aeração (GRZESIAK et al., 2013) e condutividade hidráulica do solo (REINERT et al., 2008), afetando a absorção de água e nutrientes.

A resposta da MSC ao T4 demonstra que a camada subsuperficialmente compactada 
proporcionou um incremento linear e constante de material até o $38^{\circ}$ DAP, contudo, em menores taxas que a Testemunha. Esses dados permitem supor que nesta condição ocorre o retardamento do crescimento, visto que sem compactação a MSC tenderia a ser máxima aos $34^{\circ}$ DAP, decaindo em seguida em função do volume limitado da coluna, como observado na Testemunha.

Com relação à $M S R$, verificou-se que a Testemunha apresentou comportamento cúbico, destacando-se o crescimento até o $31^{\circ}$ DAP e decréscimo a partir deste período. O T3 e o T4 proporcionaram crescimentos lineares ao longo do período de avaliação, e, o T1 e o T2 não obtiveram ajuste em função da época de avaliação (Figura 3C). Assim, constata-se que a camada compactada localizada na superfície do solo pode estagnar o desenvolvimento das raízes, resultando no aumento da relação parte aérea/raiz, como observado por Grzesiak (2009), enquanto que a camada compactada subsuperficialmente pode limitar o desenvolvimento, devido ao maior volume de solo explorado. 
Figura 2. Efeitos dos tratamentos sobre a matéria seca das folhas (A), do caule (B), das raízes (C) e total (D), número de folhas $(E)$, área foliar $(F)$, diâmetro do caule $(G)$, volume radicular $(H)$, taxa de crescimento absoluto (I) e relativo (J) em função do tempo após o transplantio.
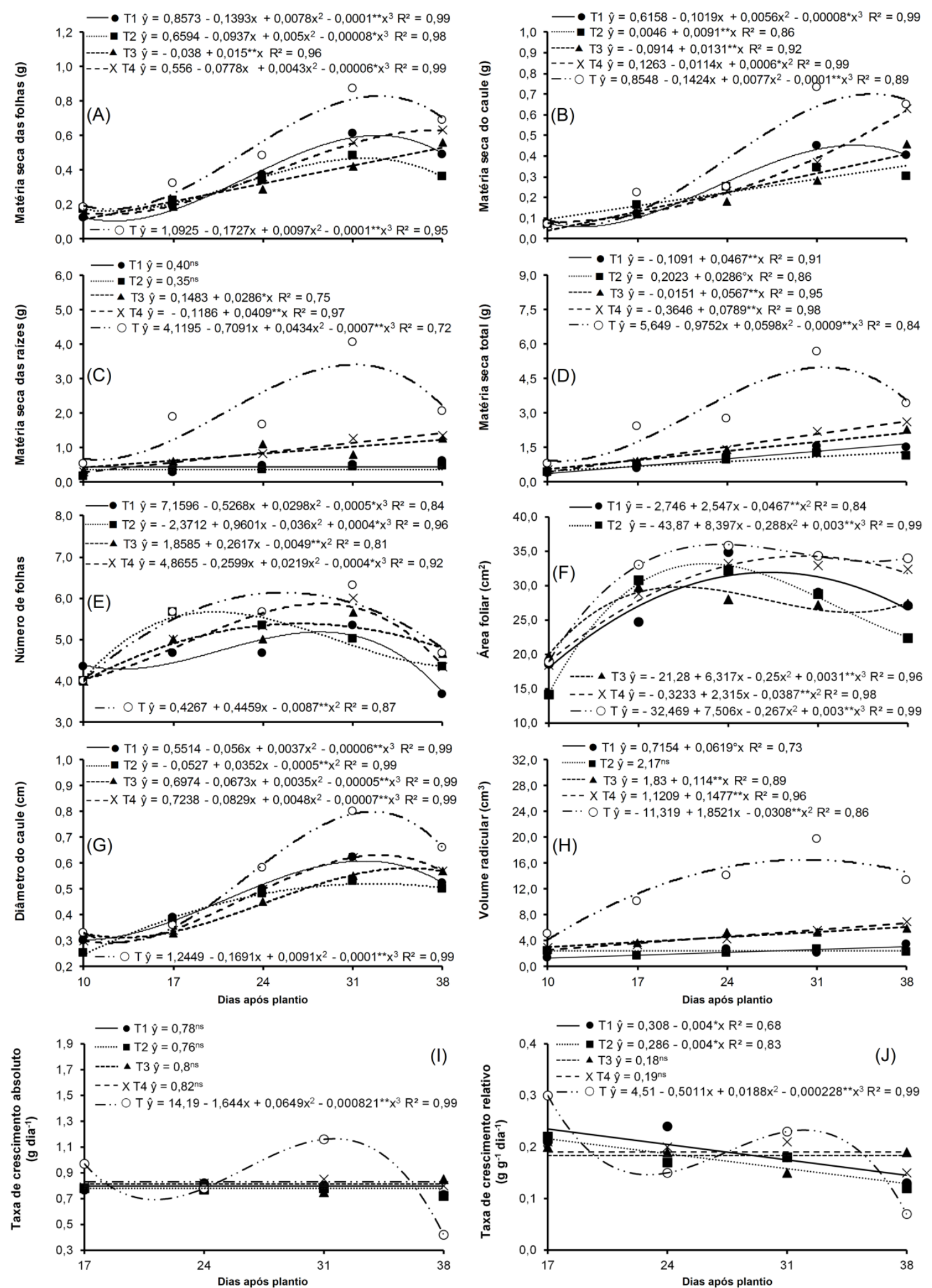

${ }^{\text {ns }}, * * e^{*}$ : não significativo e significativo a 5 e $1 \%$ pelo teste $t$, respectivamente.

A massa seca da raiz (MSR) e a massa seca total (MST) foram maiores na Testemunha $(2,034 \mathrm{~g}$ e $2,997 \mathrm{~g}$, respectivamente), não havendo diferença entre os demais tratamentos $(\leq 0,863$ e $\leq 1,527 \mathrm{~g}$, respectivamente). Esses resultados demonstram que 0 efeito da 
compactação do solo caracterizado por DS $\geq 1,5 \mathrm{~g}$ $\mathrm{cm}^{-3}$, influenciam negativamente essas variáveis, independentemente da localização da camada compactada. A redução da produção de matéria seca afeta o potencial econômico da cultura, tendo em vista que, esta variável se correlaciona com a produtividade (FREDDI et al., 2009a; 2009b).

O NF não apresentou significância em relação aos tratamentos, quando comparado a testemunha aos demais tratamentos por meio da análise de contrastes. O NF aumentou independente dos tratamentos, com valor máximo observado na Testemunha, que foi de aproximadamente 7 folhas planta ${ }^{-1}$ (Figura 2E). Em trabalhos com outras culturas, Bonelli et al. (2011), Farias et al. (2013) e Ohland et al. (2014), observaram decréscimo do NF em função do aumento da densidade do solo.

Ao avaliar o NF na cultura do milho, Brito et al. (2013) em seus resultados observaram não haver diferença significativa, contudo, a medida que se aumentou a umidade do solo houve um acréscimo da área foliar para a cultura.

A AF aumentou independentemente dos tratamentos, com o valor máximo observado ocorrido na Testemunha, que foi de aproximadamente $495,1 \mathrm{~cm}^{2}$ aos 22 DAP, os quais decresceram a partir do 24 DAP, independente do tratamento. De forma geral, os tratamentos que foram submetidos à camada de compactação aos $0-3 \mathrm{~cm}$, proporcionaram baixos valores de $A F$, em relação aos tratamentos em que a camada de compactação foi aos 8,5-11,5 $\mathrm{cm}$ indicando uma restrição do desenvolvimento da cultura (Figura 2F).
O maior valor do DC foi observado aos $31^{\circ}$ DAP em quase todos os tratamentos (exceção para T3), com maior valor na Testemunha, aproximadamente $0,76 \mathrm{~cm}$ (Figura 2G). Esse comportamento sugere a presença de um mecanismo de resposta na cultura do milho, em função do estresse promovido pela compactação. A formação da camada compactada promove o aumento da resistência a penetração do sistema radicular e a redução do fluxo hídrico no perfil do solo, diminuindo o volume de solo explorado pelas raízes e, consequentemente, a disponibilidade de água e nutrientes. A compactação do solo também pode reduzir a transpiração foliar e a taxa fotossintética, como observado por Souza et al. (2018), comprometendo severamente o crescimento da cultura.

Apesar do valor do diâmetro do caule (DC) ser maior na testemunha, constata-se que não há diferença significativa em relação aos tratamentos T1 e T4 (Tabela 3). Estes resultados sugerem que na camada superficial se tem a redução do $D C$ com DS de $1,7 \mathrm{~g} \mathrm{~cm}^{-3}$, enquanto que na camada subsuperficial a redução já ocorre na DS de $1,5 \mathrm{~g} \mathrm{~cm}^{-3}$. A redução do $D C$ com a compactação também foi observada por Farias et al. (2013) em feijão guandú anão, demonstrando que a respostas morfológicas ao impedimento físico do solo também ocorrem em outras culturas agrícolas. A redução do DC pode ocasionar problemas relacionados ao acamamento na cultura do milho, principalmente em regiões que apresentam ventos constantes, como o município de Areia-PB, localizado no planalto da Borborema. 
Tabela 3. Efeito da compactação na morfologia do milho cultivado em Argissolo Vermelho-Amarelo distrófico, Areia-PB.

\begin{tabular}{cccccc}
\hline Tratamento & MSF & MSC & MSR & MST & NF \\
\hline T1 & $0,355 \mathrm{a}$ & $0,259 \mathrm{a}$ & $0,399 \mathrm{~b}$ & $1,012 \mathrm{~b}$ & $4,53 \mathrm{a}$ \\
T2 & $0,313 \mathrm{a}$ & $0,223 \mathrm{a}$ & $0,354 \mathrm{~b}$ & $0,891 \mathrm{~b}$ & $4,87 \mathrm{a}$ \\
T3 & $0,323 \mathrm{a}$ & $0,223 \mathrm{a}$ & $0,834 \mathrm{~b}$ & $1,346 \mathrm{~b}$ & $4,87 \mathrm{a}$ \\
T4 & $0,380 \mathrm{a}$ & $0,285 \mathrm{a}$ & $0,863 \mathrm{~b}$ & $1,527 \mathrm{~b}$ & $4,93 \mathrm{a}$ \\
T & $0,509 \mathrm{a}$ & $0,382 \mathrm{a}$ & $2,034 \mathrm{a}$ & $2,997 \mathrm{a}$ & $5,27 \mathrm{a}$ \\
\hline DMS* $^{*}$ & 0,220 & 0,207 & 0,822 & 1,041 & 0,91 \\
DMS** $^{*}$ & 0,197 & 0,186 & 0,737 & 0,933 & 0,815 \\
\hline T1 & AF & DC & VR & TCA & TCR \\
\hline T2 & $26,873 \mathrm{a}$ & $0,456 \mathrm{ab}$ & $2,20 \mathrm{c}$ & $0,780 \mathrm{a}$ & $0,189 \mathrm{a}$ \\
T3 & $25,667 \mathrm{a}$ & $0,429 \mathrm{~b}$ & $2,17 \mathrm{c}$ & $0,766 \mathrm{a}$ & $0,171 \mathrm{a}$ \\
T4 & $26,440 \mathrm{a}$ & $0,446 \mathrm{~b}$ & $4,57 \mathrm{~b}$ & $0,800 \mathrm{a}$ & $0,182 \mathrm{a}$ \\
T & $29,160 \mathrm{a}$ & $0,465 \mathrm{ab}$ & $4,67 \mathrm{~b}$ & $0,815 \mathrm{a}$ & $0,192 \mathrm{a}$ \\
DMS* & $31,240 \mathrm{a}$ & $0,548 \mathrm{a}$ & $12,40 \mathrm{a}$ & $0,834 \mathrm{a}$ & $0,189 \mathrm{a}$ \\
DMS** & 8,17 & 0,099 & 1,74 & 0,073 & 0,048 \\
\hline MSF & 7,327 & 0,089 & 1,56 & 0,066 & 0,043 \\
\hline
\end{tabular}

MSF: matéria seca foliar; MSC: matéria seca do caule; MSR: matéria seca da raiz; MST: matéria seca total; NF: número de folhas; AF: área foliar; DC: diâmetro do caule; VR: volume radicular; TCA: taxa de crescimento absoluto; TCR: taxa de crescimento relativo; Médias seguidas pela mesma letra, na coluna, não diferem entre si $(P<0,05)$ pelo teste Tukey; *DMS referente ao teste Tukey; **DMS referente à análise de contrastes ortogonais.

No T2, a combinação da densidade de 1,7 $\mathrm{g} \mathrm{cm}^{-3}$ com a camada compactada na profundidade de $0-3 \mathrm{~cm}$ foi o suficiente para restringir o crescimento do VR. Nessas condições recomenda-se o uso de práticas que possam reduzir a DS, como o uso de plantas de cobertura ou mobilização com implementos agrícolas. Reinert et al. (2008) encontraram a densidade crítica de $1,85 \mathrm{~g} \mathrm{~cm}^{-3}$ em Argissolo Vermelho, denotando a necessidade de revolver o solo com escarificador, ou subsolador, dependendo da localização da camada compactada, uma vez que, essa densidade dificulta o crescimento de plantas de coberturas.

A taxa de crescimento absoluto (TCA) refere-se à velocidade média de crescimento da planta ao longo do período de observação, desta forma, com alta correlação com a velocidade de crescimento (SANTOS et al., 2013). Essa taxa está correlacionada diretamente com o crescimento da parte aérea da planta, principalmente em relação ao número de folhas e a área foliar (PINZÓN-TORRES; SCHIAVINATO, 2008; LOPES et al., 2009), responsáveis pela fotossíntese e ao acúmulo de biomassa da planta.

$\mathrm{Na}$ Figura 2l, verifica-se que a TCA permaneceu praticamente constante em todos os tratamentos durante o período experimental, com exceção da Testemunha ( $T$ ), na qual foi observado um aumento dessa taxa até o $31^{\circ} \mathrm{DAP}$. A partir desse momento, houve uma redução da
TCA, em função da diminuição do número das folhas. Provavelmente, a partir desse período a massa de solo disponível para o crescimento pleno do milho pode ter sido insuficiente, mesmo não havendo impedimento da compactação e aumento da densidade do solo, sendo limitado, provavelmente, pela menor disponibilidade de água, nutrientes e trocas gasosas do solo.

Embora a taxa de crescimento absoluto indique a velocidade de crescimento da planta, para os fisiologistas é mais interessante expressar a taxa de crescimento, segundo uma base comum, o próprio peso da planta (LIMA et al., 2007). Para isso, é utilizada a taxa de crescimento relativo (TCR), definida por Aguiar Neto et al. (2000), como um índice de eficiência, já que representa a capacidade da planta em produzir material novo.

A TCR reduziu de forma linear nos tratamentos T1 e T2 (Figura 2J). Nesses tratamentos, o volume de solo disponível para implantação do milho após a germinação diminuiu pela camada superficial compactada nos primeiros $3 \mathrm{~cm}$ de profundidade. Isso afetou a emergência das folhas pelo menor volume do sistema radicular nesses tratamentos, resultando em um menor número de folhas com relação à testemunha em todo o período de observação. Além disso, a partir do $25^{\circ} \mathrm{DAP}$, constatou-se reduções do número de folhas e da área foliar, 
afetando diretamente a fotossíntese e, consequentemente, o crescimento do milho.

$\mathrm{Na}$ Testemunha (T), a TCR variou com o tempo, tendendo à sua diminuição, sendo esse comportamento observado por outros autores (SANTOS et al., 2013). Decréscimos nos valores de TCR ao longo do ciclo da cultura são comuns para a maioria das espécies, com o aumento da massa acumulada pela planta ocorre aumento da necessidade de fotoassimilados para a manutenção dos órgãos já formados (SILVA et al., 2010), ou seja, maior relação dreno:fonte.

O volume radicular (VR) foi afetado negativamente em todos os tratamentos, tendo em vista que, os tratamentos T1, T3 e T4 apresentaram crescimento linear, contudo, bem abaixo do constatado na Testemunha, enquanto que o T2 não apresentou crescimento significativo (Figura $2 \mathrm{H}$ ). De acordo com Bergamin et al. (2010), o aumento da densidade do solo promove a redução da macroporosidade e porosidade total, elevando a resistência do solo à penetração do sistema radicular do milho, principalmente até $0,10 \mathrm{~m}$ de profundidade. Com relação a localização da camada compactada, verificou-se que, ao ocorrer na superfície do solo, as limitações iniciaram na germinação e estabelecimento da plântula, consumindo mais energia da reserva das sementes para obtenção de água e nutrientes, e formação do sistema radicular, reduzindo o VR.

O volume radicular (VR) decresceu com o aumento da densidade do solo, sendo mais acentuado ao ocorrer na camada superficial do solo. Portanto, constata-se que a camada compactada na superfície é mais prejudicial ao sistema radicular da planta do que a camada subsuperfícial, tendendo a reduzir ainda mais a produtividade da cultura.

Sob o efeito da compactação, reduz-se a profundidade efetiva do sistema radicular, o que diminui, consequentemente, a disponibilidade de água e nutrientes para a planta. Em trabalho realizado por Grzesiak (2009), constatou-se que o déficit hídrico ocasionado pela compactação não reduz somente a matéria seca das raízes, mas também a matéria seca da parte aérea, o número de folhas e a área foliar. O decréscimo da matéria seca das raízes, ocorre devido a redução do fluxo de fotoassimilados das folhas em direção às raízes (TAIZ et al., 2017), explicando a influência negativa na parte aérea da planta.

\section{CONCLUSÕES}

O aumento da densidade dentro das camadas reduziu o desenvolvimento radicular e a produção de matéria seca total, com maior magnitude quando a compactação ocorre na camada superficial.

Houve redução do crescimento da parte aérea com o aumento da densidade do solo, independente da profundidade da camada compactada.

\section{REFERÊNCIAS}

AGUIAR NETTO, A.O.; RODRIGUES, J.D.; PINHO, S.Z. Análise de crescimento na cultura da batata submetida a diferentes lâminas de irrigação. Pesquisa Agropecuária Brasileira, v.35, n.5, p.901-907,

2000.http://dx.doi.org/10.1590/s0100-

204X2000000500006

ALVARES, C. A.; STAPE, J. L.; SENTELHAS, P. C.; GONÇALVES, J. L. M.; SPAROVEK, G. Köppen's climate classification map for Brazil. Meteorologische Zeitschrift, v.22, n.6, p.711728, 2014. http://dx.doi.org/10.1127/09412948/2013/0507

BERGAMIN, A.C.; VITORINO, A.C.T.; FRANCHINI, J.C.; SOUZA, C.M.A.; SOUZA, F.R. Compactação em um Latossolo Vermelho distroférrico e suas relações com o crescimento radicular do milho. Revista Brasileira de Ciência do Solo, v.34, n.3, p.681-691, 2010. http://dx.doi.org/10.1590/S010006832010000300009

BONELLI, E.A.; SILVA, E.M.B.; CABRAL, C.E.A.; CAMPOS, J.J.; SCARAMUZZA, W.L.P.; POLIZEL, A.C. Compactação do solo: Efeitos nas características produtivas e morfológicas dos capins Piatã e Mombaça. Revista Brasileira de Engenharia Agrícola e Ambiental, v.15, n.3, p.264-269, 2011. http://dx.doi.org/10.1590/S141543662011000300007

BRITO, M.E.B.; ARAÚJO FILHO, G.D.; WANDERLEY, J.A.C.; MELO, A.S.; COSTA, F.B.; FERREIRA, M.G.B. Crescimento, fisiologia e produção do milho doce sob estresse hídrico. Bioscience Journal, v.29, n.5, p.1244-1254, 2013.

CABRAL, C.E.A.; SILVA, E.M.B.; BONELLI, E.A.; SILVA, T.J.A.; CABRAL, C.H.A.; SCARAMUZZA, 
W.L.M.P. Compactação do solo e macronutrientes primários na Brachiaria brizantha cv. Piatã e Panicum maximum cv. Mombaça. Revista Brasileira de Engenharia Agrícola e Ambiental, v.16, n.4, p.362-367, 2012. http://dx.doi.org/10.1590/S141543662012000400005.

CONAB. Acompanhamento da safra brasileira de grãos - Safra 2018/2019. Brasília: Conab, 2019.

DONAGEMA, G.K.; CAMPOS, D.V.B.; CALDERANO, S.B.; TEIXEIRA, W.G.; VIANA, J.H.M. (Org.). Manual de métodos de análise de solos. 2.ed. Rio de Janeiro: Embrapa Solos, 2011.

FARIAS, L.N.; BONFIM-SILVA, E.M.; PIETROSOUZA, W.; VILARINHO, M.K.C.; SILVA, T.J.A.; GUIMARÃES, S.L. Características morfológicas e produtivas de feijão guandu anão cultivado em solo compactado. Revista Brasileira de Engenharia Agrícola e Ambiental, v.17, n.5, p.497-503, 2013. http://dx.doi.org/10.1590/S141543662013000500005

FERREIRA, D.F. Sisvar: a computer statistical analysis system. Ciência e Agrotecnologia, v.35, n.6, p.1039-1042, 2011. http://dx.doi.org/10.1590/S1413-

70542011000600001

FREDDI, O.S.; CENTURION, J.F.; DUARTE, A.P.; LEONEL, C.L. Compactação do solo e produção de cultivares de milho em Latossolo Vermelho. I Características da planta, solo e índice S. Revista Brasileira de Ciência do Solo, v.33, n.4, p.793803, 2009a. http://dx.doi.org/10.1590/S010006832009000400006

FREDDI, O.S.; CENTURION, J.F.; DUARTE, A.P.; PERES, F.S.C. Compactação do solo e produção de cultivares de milho em Latossolo Vermelho. II Intervalo hídrico ótimo e sistema radicular. Revista Brasileira de Ciência do Solo, v.33, n.4, p.805-818, 2009b. http://dx.doi.org/10.1590/S010006832009000400006

GRZESIAK, M.T. Impact of soil compaction on root architecture, leaf water status, gas exchange and growth of maize and triticale seedlings. Plant Root, v.3, p.10-16, 2009. http://doi.org/10.3117/plantroot.3.10
GRZESIAK, S.; GRZESIAK, M.T.; HURA, T.; MARCINSKA, I.; RZEPKA, A. Changes in root system structure, leaf water potential and gas exchange of maize and triticale seedlings affected by soil compaction. Environmental and Experimental Botany, v.88, p.2-10, 2013.http://dx.doi.org/10.1016/j.envexpbot.2012 .01 .010

KLEIN, C.; KLEIN, V.A. Influência do manejo do solo na infiltração de água. Revista Monografias Ambientais, v.13, n.5, p.3915-3925, 2014.

LIMA, J.F.; PEIXOTO, C.P.; LEDO, C.A.S. Índices fisiológicos e crescimento inicial de mamoeiro (Carica papaya L.) em casa de vegetação.Ciência e Agrotecnologia, v. 31, n. 5, p. 1358-1363, 2007. http://dx.doi.org/10.1590/\$1413-

70542007000500013

LOPES, J.P.; MACHADO, E.C.; DEUBER, R.; MACHADO, R.S. Análise de crescimento e trocas gasosas na cultura de milho em plantio direto e convencional. Bragantia, v.68, n.4, p.839-848, $2009 . \quad$ http://dx.doi.org/10.1590/S000687052009000400003

MANCUSO, M.A.; FLORES, B.A.; ROSA, G.M. SCHROEDER, J.K.; PRETTO, P.R.P. Características da taxa de infiltração e densidade do solo em distintos tipos de cobertura de solo em zona urbana. Revista Monografias Ambientais, v.14, n.1, p.2890-2998, 2014.

MIRANSARI, M. Corn (Zea mays L.) growth as affected by soil compaction and arbuscular mycorrhizal fungi. Journal of Plant Nutrition, v.36, n.12, p.853-1867, 2013. http://dx.doi.org/10.1080/01904167.2013.81672 9

OHLAND, T.; LANA, M.C.; FRANDOLOSO, J.F.; RAMPIM, L., BERGMANN, J.R.; CABREIRA, D.T. Influência da densidade do solo no desenvolvimento inicial do pinhão-manso cultivado em Latossolo Vermelho eutroférrico. Revista Ceres, v.61, n.5, p.622-630, 2014. http://dx.doi.org/10.1590/0034737X201461050004

PINZÓN-TORRES, J.A.; SCHIAVINATO, M.A. Crescimento, eficiência fotossintética e eficiência do uso da água em quatro espécies de 
leguminosas arbóreas tropicais. Hoehnea, v.35, n.3, p.395-404, 2008.

REINERT, D.J.; ALBUQUERQUE, J.A.; REICHERT, J.M.; AITA, C.; ANDRADA, M.M.C. Limites críticos de densidade do solo para o crescimento de raízes de plantas de cobertura em Argissolo Vermelho. Revista Brasileira de Ciência do Solo, v.32, n.5, p.1805-1816, 2008. http://dx.doi.org/10.1590/S0100-

06832008000500002

RODRIGUES, P.N.F.; ROLIM, M.M.; BEZERRA NETO, E.; PEDROSA, E.M.R.; OLIVEIRA, V.S. Crescimento e composição mineral do milho em função da compactação do solo e da aplicação de composto orgânico. Revista Brasileira de Engenharia Agrícola e Ambiental, v.13, n.1, p.9499, 2009. http://dx.doi.org/10.1590/S141543662009000100014

SANTOS, V.M; MELO, A.V.; SIEBENEICHLER, S.C.; CARDOSO, D.P.; BENÍCIO, L.P.F.; VARANDA, M.A.F. Physiological indices of seedlings of maize (Zea mays L.) under the action of biostimulants. Journal of Biotechnology and Biodiversity,v.4, n.3, 2013.http://dx.doi.org/10.1590/S141370542008000300021

SILVA, P.I.B.; NEGREIROS, M.Z.; MOURA, K.K.C.F. FREITAS, F.C.L.; NUNES, G.R. LIMA, P.S.; GRANGEIRO, L.C. Crescimento de pimentão em diferentes arranjos espaciais. Pesquisa Agropecuária Brasileira, v.45, n.2, p.132-139, 2010. http://dx.doi.org/10.1590/S0100-

204X2010000200003

SORACCO, C. G.; LOZANO, L. A.; VILLARREAL, R.; PALANCAR, T. C.; COLLAZO, D. J.; SARLI, G. O.; FILGUEIRA, R. R. (2015). Effects of compaction due to machinery traffic on soil pore configuration. Revista Brasileira de Ciência do Solo, v.39, n.2,p.408415,2015.https://dx.doi.org/10.1590/01000683rb cs20140359

SOUZA, R. F. S.; SANTOS, D.; PEREIRA, W. E.; MACEDO, F. L.; VENDRUSCOLO, J. Gas exchange and photochemical efficiency in lima bean genotypes grown in compacted soils. Revista Caatinga, v.31, n.2,p. 306 - 314, 2018.http://dx.doi.org/10.1590/198321252018v31n206rc
TAIZ, L.; ZEIGER, E.; MOLLER, I. M.; MURPHY, A. Fisiologia e desenvolvimento vegetal. 6.ed. Porto Alegre: Artmed, 2017.

Recebido para publicação em 26/08/2018

Revisado em 28/01/2019

Aceito em 28/01/2019 